\title{
XLI. Determination of Young's Modulus (adiabatic) for glass
}

\section{Chichester A. Bell M.B. \& C. Chree F.R.S.}

To cite this article: Chichester A. Bell M.B. \& C. Chree F.R.S. (1905) XLI. Determination of Young's Modulus (adiabatic) for glass, Philosophical Magazine Series 6, 9:52, 413-424, DOI: 10.1080/14786440509463295

To link to this article: http://dx.doi.org/10.1080/14786440509463295

册 Published online: 08 Jun 2010.

Submit your article to this journal $[\pi$

Џ Article views: 2

Q View related articles $\asymp$ 
viz. :- $\cdot 50, \cdot 45, \cdot 41, \cdot 40, \cdot 345, \cdot 35, \cdot 35$; showing that, beyond a certain extent, the leak is not further reduced by pumping out the vapour. These experiments indicate that most of the effect is not due to the phosphorus vapour surrounding the wire, but rather to that which has been absorbed by the superficial portions of the platinum. This view appears, without violent straining, to offer a satisfactory explanation of all the effects which have been observed; but it does not seem advisable to lay much stress on these somewhat refined theoretical points, as it is scarcely possible to test them experimentally as yet.

It might be thought that this effect was only a case of the ordinary leak produced when phosphorus oxidizes in air, due to traces of air left inside the apparatus. This view seems to be rendered quite untenable by the fact that the hot platinum discharges only positive, and not negative electricity. In addition to this, it takes no account of the very marked chemical action between the phosphorus and the hot metal.

In conclusion the author wishes to thank Prof. Thomson for his valuable advice and criticism during the course of these experiments, which were carried out in the Cavendish Laboratory.

XLI. Determination of Young's Modulus (Adiabatic) for Glass. By Chrchester A. BhLl, M.B. With an Appendix by C. ChREe, F.R.S.*

A LTHOUGH the elastic constants of glass have been A the subject of many investigations, it is not easy to make use of the published results in any experimental inquiry into which these enter. The characteristics of the specimens examined are usually so vaguely given, and the composition of the material is so variable, that it is never safe to assume the identity of any sample purchesed in the shops with one of ascertained properties.

This difficulty was acutely felt by the writer in the course of a series of experiments in which a tolerably exact knowledge of the value of Young's Modulus (adiabatic) for different kinds of glass was all-important. The results of these experiments showed variations which it was impossible to account for by any justifiable assumptions, and accordingly it became necessary to determine the required constant by experiments on specimens of the glass actually employed, the method selected for this purpose being the simplest of all-the acoustical.

* Communicated by the Physical Society: read January 27, 1905. 
So far as can be judged from a cursory examination of the literature of the subject, this method has been but little used in the case of glass, doubtless because of the well-known difficulty of obtaining perfectly uniform rods of this material of any considerable length. The original plan of these experiments was simply to determine the tones given by longitudinal vibration of a number of rods (or tubes) of each kind of glass ; to cut each of them into ten approximately equal segments; and by weighing and measuring the segments to construct for each rod a diagram representing the variations in its cross-section from end to end. It was expected that, of the more nearly uniform of the original rods, a few might thus be selected, from the tones of which Young's Modulus might be calculated.

Inspection of the diagrams showed, however, that of the many rods examined not one showed such an approach to uniformity as to be suitable for the object in view. But, taking as a standard for comparison the mean value of the product, number of vibrations per second $x$ twice length of rod, for each bundle, it was possible in a general way to connect the variation from this mean exhibited by each rod with its most marked irregularities; and this observation suggested that it might be possible, by the aid of the diagrams, to calculate for each rod an "addition to length" which would enable the velocity of sound through it to be calculated from its rate of vibration as if the cross-section were constant-a correction analogous to that given by Lord Rayleigh * for tluid columns of slightly variable section. Trial showed that this was certainly possible; and on mentioning the matter to Dr. Chree, to whom I am indebted for his cordial interest, he kindly undertook to look into it, and bas given in the Appendix to this Note the mathematical proof that the correction, somewhat empirically applied, was strictly in accordance with theory. The necessary correction is, in fact, given by Lord Rayleigh's formula with reversed sign.

In the experiments quoted below, tuning-forks of high frequency were not available; the product $n \times 2 l$ for the glass rods was therefore determined as follows. Bessemer steel rods of remarkable uniformity as regards diameter and texture are now easily procurable. Three such rods from the same drawing, $\frac{3}{8}$ of an inch in diameter, when cut to exactly the same length, about 11 feet, and clamped centrally by means of corks in a vertical position $f$, gave, on being struck

* 'Theory of Sound,' 1st edition, vol. ii. p. 61 .

+ The note given by a rod of these dimensions is distinctly raised in pitch when it is fixed horizontally. 
endwise, notes so nearly identical in pitch that beats were scarcely perceptible. This trial was carried out in the manner described farther on, and every precaution taken to secure uniformity of temperature. In the course of subsequent experiments many opportunities presented themselves of comparing the notes given by pieces of these bars of approximately equal length, and the differences not accounted for were always so small as to be unimportant, the only serious difference noted amounting to about six vibrations per second in the case of two pieces of exactly equal length, about $40 \mathrm{cms}$.

To determine the velocity of sound in the steel rods, the length of one of them was cautiously altered by cutting and filing until its note nearly coincided with that of a König fork giving 1024 double vibrations per second ; and, subsequently, taking advantage of a spell of cold weather, when room temperature had been long constant at $0^{\circ}$, rod and fork were compared together, beats being counted for 20 seconds. According to König the rate of his forks, standardized at $20^{\circ} \mathrm{C}$, increases by 000118 per cent. for each degree below standard temperature. Witl these data, the product $n \times 2 l$ for the steel bar was found to be

\section{$516040 \mathrm{cms}$. per second at $0^{\circ}$.}

Similarly favourable opportunities did not occur for testing the other bars at $0^{\circ}$; but repeated comparisons of the bars with each other, and with 768 and 896 König forks at other temperatures, left no doubt of the substantial accuracy of this determination.

Some very careful determinations of the velocity of sound in rods of varions metals and of St. Gobain glass, at tem. peratures ranging from $0^{\circ}$ to $100^{\circ} \mathrm{C}$, have been made by Mayer*, who found for a rod of Bessemer steel at $0^{\circ}$ $\mathrm{V}=515090 \mathrm{cms}$. per sec. In view of possible variations in the composition of the metal, the agreement must be considered satisfactory.

According to Mayer also the velocity of sound in such a rod diminishes by 2 per cent. when the temperature rises from $0^{\circ}$ to $20^{\circ}$, or by nearly $50 \mathrm{cms}$. per sec. for each degree.

With these data the rates of vibration of the steel rods here employed were calculated, measurements of length being throughout made by a steel metre-seale, the very trifling errors of which had been determined at Kew.

In the experiments with glass, a steel rod was first cut giving a note higher in pitch than any one of the bundle of

* "Researches in Acoustics," by Alfred M. Mayer, Phil. Mag. [5] vol. xli. p. 168. 
rods or tubes under examination ; and the lengths of these were gradually reduced by cutting and grinding, until each gave a note differing from that of the steel by about 4 or $\tilde{5}$ vibrations per second. In cutting an ordinary glass knife was used, but the trimming of the ends, and small alterations of length, were effected by lightly pressing the ends against a sheet of moderately coarse emery-cloth clamped on the face of a circular wooden disk which was rapidly rotated in a lathe. During the comparison of tones, the steel rod was simply balanced on the corner of a table, and the glass rod held at its centre in the hand, both rods being struck endwise by a light wooden mallet.

After this preliminary adjustment, the bundle of rods was laid aside until its temperature might be assumed to be that of the room. Each rod was then passed through a hole in a short cylindrical cork placed at such a point-not necessarily the centre-that the vibration was of maximum persistence, and mounted on a board side by side with the similarly supported steel rod.

A cone or funnel was fixed on the board so that its wider end embraced one pair of the rod ends, while its narrower end was connected by rubber tubing with a short length of glass tube pushed well into the ear-cavity. Beats due to the rod vibrations were thus heard with the greatest distinctness. To throw the rods into vibration, two small "pneumatic bammers" were arranged to deliver light hlows on their distant ends. Each hammer was formed of a cylinder of wood about 5 cms. in length, cut from an ordinary pen-handle, lying within a slightly wider tube of glass in which it could just slide freely. A perforated cork or a section of rubler tubing, forced into the glass tube, kept the cylinder lying normally just within one of its ends; the other drawn-out end was connected by thin rubber tubing with a bag such as is used for pneumatic bells, which could be placed in any convenient position. By tapping on this bag with the finger the little wooden cylinder was sharply projected from, and as sharply drawn back into, the glass, after impact on the rod end; whilst by pressing gently on the bag the hammer was caused to rest against the rod, at once checking its motion. The rods could thus be thrown into vibration either alternately or simultaneously, the force of the blows delivered being under complete control. This little device, which I have found superior to any other mechanical or electrical arrangement, has proved of eminent service in a number of acoustical experiments. Thus in working with tuning-forks it makes it unnecessary for the operutor to approach them- 
sometimes a matter of importance ; whilst in experiments on rods, hammer and rod may be enclosed in a tube, which is then immersed in a water or steam bath.

The beats produced by the simultaneous vibration of the glass and steel rods were, as a rule, simply estimated by comparison with those of a watch. The most successful of more exact metbods tried consisted in timing the oscillations of a heavy ball attached to a string to coincide with the period of the beats, by altering the length of the string, the rate of the pendulum being subsequently ascertained by means of a watch. But a moderate amount of practice enables one to make a pretty exact estimate of the frequency of the beats when this is in the neighbourhood of four or five per second. It is not advisable to attempt to bring steel and glass rod more closely into unison: as a rule the vibrations of thin glass rods, especially if these are rather irregular, die out so rapidly that the apparent absence of beats is no criterion of exact synchronism.

In every case, the sense of the difference between steel and glass rod was positively ascertained in the usual way by means of a spring-brass rider which could be fixed on the steel bar. This was more than usually important, since the fundamental tone of an irregular rod is certain to be accompanied by anharmonic overtones.

In the way described, the product $n \times 2 l$ is ensily and rapidly found for a number of thin rods. The correction, $\Delta \bar{l}$, to be applied to the observed length $l$ of a free-free irregular rod vibrating longitudinally in its gravest mode, is (see Appendix)

$$
\Delta l=\int_{0}^{l} \frac{\delta \mathrm{S}}{\mathrm{S}_{0}} \cdot \cos \frac{2 \pi z}{l} d z
$$

where $\delta S$ is the difference, positive or negative, between the cross-section at the point $z$ and its mean value, $\mathrm{S}_{0}$, for the whole rod.

Now an exact determination of $\mathrm{S}$ throughout even a single rod of considerable length would be a matter of some difficulty; and as rods and tubes are never quite free from knots and streaks, very often not homogeneous throughout, and only exceptionally properly annealed, would in the end lead to no high degree of accuracy. In these experiments I have, as a rule, been satisfied to divide each rod into ten nearly equal lengths; after suitable trimming of the ends of each piece on the emery disk, to determine its length to the nearest tenth millinetre, and its weight to within one milligramme; and to take $\frac{\text { weight }}{\text { length }}$ as a measure of $S$, supposed 
to be uniform throughout the segment, $S_{0}$ being similarly determined for the whole rod. The values of the integral

$$
\int \cos \frac{2 \pi z}{l} \cdot d z
$$

between the limits $z=0, z=\frac{1}{10} l ; z=\frac{1}{10} l, z=\frac{2}{10} l$, and so on, are, to the degree of approximation considered necessary, and in order, $\frac{l}{2 \pi}$ muitiplied by the fractions

$$
\begin{array}{cccccccccc}
+ & + & - & - & + & + \\
.59 & .36 & 0 & \cdot 36 & .59 & .59 & \cdot 36 & 0 & .36 & .59
\end{array}
$$

The total correction thus becomes

$$
\Delta l=\frac{l}{2 \pi}\left(\frac{\cdot 59\left(\mathrm{~S}_{1}-\mathrm{S}_{0}\right)+\cdot 36\left(\mathrm{~S}_{2}-\mathrm{S}_{0}\right)-\cdot 36\left(\mathrm{~S}_{4}-\mathrm{S}_{0}\right) \ldots+\cdot 59\left(\mathrm{~S}_{10}-\mathrm{S}_{0}\right.}{\mathrm{S}_{0}}\right)
$$

the third and eighth sections being omitted. Inspection of the diagrams will show at once if the omission is justified.

The lists below inelude three rods in which the subdivision was subsequently made into twenty parts. In two cases the final result was practically unchanged ; in the third the value of $a$ was raised only 3 metres per second. On the whole, further subdivision did not appear to be necessary.

Finally, we get for the "velocity of sound"

$$
a=2 n(l+\Delta l),
$$

and for Young's Modulus (adiabatic)

$$
\mathrm{E}^{\prime}=a^{2} \rho,
$$

where $\rho$ is the density referred to water at $4^{\circ} \mathrm{C}$.

In the tables are given the values of $a$ and $E^{\prime}$ reduced to $0^{\circ}$. According to Mayer (loc. cit.) Young's Modulus for St. Gobain glass $(\rho=2 \cdot 545)$ diminishes by 1.16 per cent. for a rise of temperature from $0^{\circ}$ to $100^{\circ} \mathrm{C}$. In a special experiment with the Gallenkamp soft German glass, a diminution of 1.12 per cent. from $5^{\circ}$ to $100^{\circ}$ was observed, closely agreeing with Mayer's determination. With Powell's flint-glass, on the other hand, the curious result was obtained that Young's Modulus is sensibly constant between the same temperature limits. This observation is quite in harmony with the results obtained by Winkelmann and Schott* for glass of the same general character. In fact, if two rods of this glass be "tuned" to the same pitch, one of them may be made very hot by passage through a gas-flame before any distinct alteration of its note can be observed. Owing to the brilliance

* "Ueber die Elasticität, etc., verschiedener Glïser," Wiedemann's Annalen, Bd. li. p. 697 (1894). 
and persistence of the tones obtained from stout and fairly uniform rods of this glass, the low value of $a$ and the absence of a temperature-coefficient, it is admirably adapted for standards of high pitch. The end of the rod on which blows are delivered may be fused, to diminish the risk of chipping, and the tuning effected by grinding the other end.

All results are given in absolute units. The density at $0^{\circ}$ has been determined from selected samples. As it was found to be slightly variable, especially in the case of flint-glass, it is given to only four figures.

It is perhaps well to point out that the occasional close agreement between the corrected and uncorrected values of $n \times 2 l$ does not imply approximate uniformity in the corresponding rod. This is far indeed from being the case.

\section{Soft German Glass.}

1. From Messrs. Gallenkamp \& Co.

Mean $n \times 2 l$ for eight rods at $14^{\circ}=527280 \mathrm{cms}$. per sec. Of these five of the best were selected for examination. Lengths about $150 \mathrm{cms} . \quad \rho_{0}($ mean $)=2.508$.

$\begin{array}{cc}n \times 2 l \text { observed. } & a \text { (corrected) cms. per sec. } \\ 527620 & 525930 \\ 523920 & 526030 \\ 517240 & 525940 \\ 525850 & 526610 \\ 528100 & \frac{526820}{} \\ & \text { Mean }= \\ & =526260 \text { at } 6^{\circ} \mathrm{C} . \\ \text { Todulus (adiabatic) or } \mathrm{E}^{\prime} & \end{array}$

Young's Modulus (adiabatic) or $\mathbf{E}^{\prime}$

$=6.95 \times 10^{11}$ dynes per sq. $\mathrm{cm}$. at $0^{\circ}$.

Eight selected thin tubes of this glass gave a mean value of $n \times 2 l$ at $6^{\circ}=525500 \mathrm{cms}$. per sec. These were not cut up.

2. From Messrs. C. E. Müller \& Co.

Mean product for 12 carefully chosen rods at $14^{\circ}=524800$. Of these six examined. Lengths about $150 \mathrm{cms} . \rho_{0}=2 \cdot 507$.

$\begin{array}{cc}n \times 2 l \text { obserred. } & a \text { (corrected) } \\ 529000 & 525490 \\ 523020 & 524780 \\ 521270 & 525400 \\ 526020 & 524760 \\ 526020 & 524720 \\ 524580 & 525100 \\ & \\ \text { Mean }=525050 \text { at } 9^{\circ} \\ =525250 \text { at } 0^{\circ} . \\ \mathrm{E}^{\prime}=6.91 \times 10^{11} \text { at } 0^{\circ} .\end{array}$


3. From Messrs. Baird \& Tatlook.

Mean product for nine rods at $9^{\circ}=525990$. Lengths about $143 \mathrm{cms}$. $\rho_{0}=2.488$.

$n \times 2 l$ observed.
524310
530640
527900
527480
517660

$a$ (corrected).
527360
527180
526710
526900
526370

Mean $a$ at $6^{\circ}=527040 \mathrm{~cm}$. per sec. at $0^{\circ}=527170$.

$$
\mathrm{E}^{\prime}=6.91 \times 10^{11} \text { at } 0^{\circ} \text {. }
$$

The last result here has been rejected. For this very irregular rod $\Delta l$ was +2.36 cms.

\section{Bohemian Gilass.}

From M̀essrs. Baird \& Tatlock. This glass was obtainable only in thin tubes, very irregular, much streaked and full of knots.

Mean product for six tubes $=513740$ at $6^{\circ}$. Lengths about 138 cms. $\rho_{0}=2 \cdot 394$.

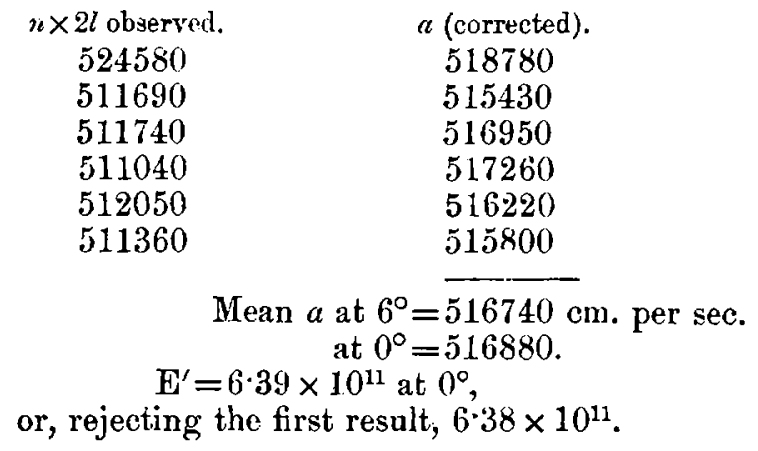

Mean $a$ at $6^{\circ}=516740 \mathrm{~cm}$. per sec. at $0^{\circ}=516880$.

The agreement here is not nearly so good as usual, as indeed was anticipated.

\section{Gauge-tube Glass.}

A hard, ferruginous, light-green glass, almost infusible, manufactured by Messrs. Powell \& Sons of Whitefriars, specially for gauge-tubes. Four carefully-chosen tubes, about $112 \mathrm{cms}$. in length, were examined. The exterual diameter 
of these tubes, about $1.3 \mathrm{~cm}$., was rather greater, in proportion to length, than was desirable, but narrower or much longer tubes were not obtainable. $\rho_{0}=2 \cdot 525$.

$n \times 2 l$ observed.
542380
539690
540570
541420

$a$ (corrected). 539820

539350

$\check{3} 39850$

539560

Mean $a$ at $9^{\circ}=539650 \mathrm{~cm}$. per sec. at $0^{\circ}=539850$.

$\mathrm{E}^{\prime}=7 \cdot 36 \times 10^{11}$ at $0^{\circ}$.

"Soft" Jena Glass.

Stout tubes, somewhat narrower than the foregoing, of length about $144 \mathrm{cms} . \quad \rho_{0}=2 \cdot 499$.

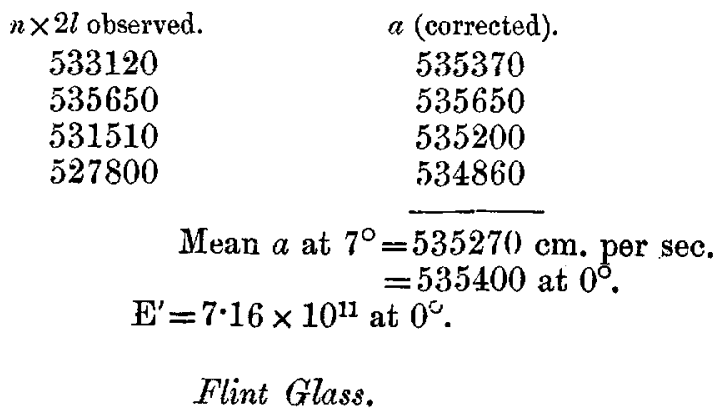

Flint Glass.

From the Whitefriars Glass-works. Mean product for ten thin rods at $3^{\circ}=409910$. Lengths about 91 cms. $\rho_{0}($ mean $)=3 \cdot 164$.

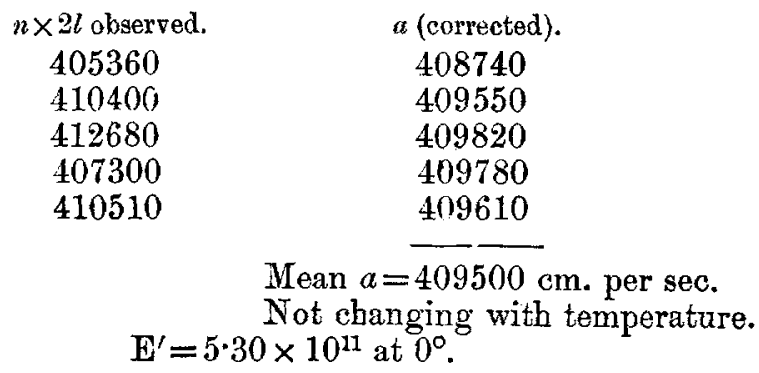

Mean $a=409500 \mathrm{~cm}$. per sec.

Not changing with temperature. $\mathrm{E}^{\prime}=5 \cdot 30 \times 10^{11}$ at $0^{\circ}$.

For this glass, the value of $E^{\prime}$ depends greatly on the amount of lead contained. For example, in two other 
specimens from the same works, but of density 3.136 at $10^{\circ} / 4^{\circ}$, an indirect determination of $\mathrm{E}^{\prime}$ gave $5.39 \times 10^{11}$.

The foregoing list includes all the rods and tubes that have been examined, with only one exception, where some gross blunder had evidently been committed. Inspection shows that discrepancies between the uncorrected products $n \times 2 l$ are reduced by 90 per cent. in the corrected values of $a$, and it is highly probable that the calculated values of $\mathbf{E}^{\prime}$ are correct to three figures.

When a glass can be obtained in thin rods or tubes-a diameter of 5 or $6 \mathrm{mms}$. seems most desirable-the experiments are easily and rapidly carried out, since no great accuracy is required in the weighing or measurement of the segments. Thick rods or tubes naturally give more trouble, especially when of hard glass, and here some care in selecting suitable specimens is desirable. Tubes which do not give persistent notes when struck should be at once rejected. Perfect uniformity is not to be expected; failing this, the best results are obtained with rods or tubes which taper continuously from one end to the other.

\section{Appendix by C. Chree, F.R.S.}

Taking the axis of the tube as axis of $z$, the origin being at one end, we have for the longitudinal displacement in the fundamental free-free vibration

$$
w=\mathrm{A} \cos k t \cos \pi \approx / l, \text {. . . . . }
$$

where $\mathrm{A}$ is a constant, $l$ the length, and $k / 2 \pi$ the frequency.

In reality $w$ varies slightly over the cross-section, but for the purpose of the present correction we may neglect this variation and also the energy answering to the lateral motion.

If the section $\mathrm{S}$ were uniform we should have-neglecting the correction for finite area of section-

$$
k / \pi=a / l, \quad \text { where } a=\sqrt{ } \mathbf{E} / \boldsymbol{\rho} .
$$

Here $\rho$ denotes the density, $E$ Young's modulus, and $\alpha$ the "velocity of sound" in the nomenclature employed by Lord Rayleigh.

$\mathrm{S}$, it should be noticed, means the sectional area of the material; in a circular tube whose outer and inner surfaces are circles of radii $r$ and $r^{\prime}, \mathrm{S}=\pi\left(r^{2}-r^{2}\right)$.

Let

$$
\mathrm{S}=\mathrm{S}_{0}+\delta \mathrm{S}, \quad \cdot \quad \cdot \cdot \cdot \cdot
$$




$$
\text { of Young's Modulus for Glass. }
$$

where $\mathbf{S}_{0}$ is constant, and $\delta \mathrm{S} / \mathbf{S}_{0}$ is supposed small everywhere along the tube.

Let $\mathrm{T}$ denote the kinetic, $\mathrm{V}$ the potential energy, then, as in Lord Rayleigh's 'Theory of Sound,'

$$
\begin{aligned}
& \mathrm{T}=\int_{0}^{l} \frac{1}{2} \rho \dot{w}^{2} \mathrm{~S} d z, \\
& \mathrm{~V}=\int_{0}^{l} \frac{1}{2} \mathrm{E}\left(\frac{d w}{d z}\right)^{2} \mathrm{~S} d z .
\end{aligned}
$$

Thence from (1) and (2)

$$
\begin{aligned}
& \mathrm{T}=\frac{1}{2} \rho \mathrm{A}^{2} k^{2} \mathrm{~S}_{0} \sin ^{2} k t \int_{0}^{l} \cos ^{2}(\pi z / l)\left(1+\delta \mathrm{S} / \mathrm{S}_{0}\right) d z \\
& \mathrm{~V}=\frac{1}{2} \mathrm{~A}^{2} \mathrm{E}(\pi / l)^{2} \cos ^{2} k t \int_{0}^{l} \sin ^{2}(\pi z / l)\left(1+\delta \mathrm{S} / \mathrm{S}_{0}\right) d z
\end{aligned}
$$

But $\mathrm{T}+\mathrm{V}$ is constant throughout the motion, and so the coefficients of $\sin ^{2} k t$ and $\cos ^{2} k t$ are equal. Equating them, we find

or

$$
\begin{aligned}
k^{2}=(\mathrm{E} / \rho)(\pi / l)^{2} \frac{\int_{0}^{l} \sin ^{2}(\pi z / l)\left(1+\delta \mathrm{S} / \mathrm{S}_{0}\right) d z}{\int_{0}^{l} \cos ^{2}(\pi z / l)\left(1+\delta \mathrm{S} / \mathrm{S}_{0}\right) d z}, & \frac{1+\frac{2}{l} \int_{0}^{l} \sin ^{2}(\pi z / l)\left(\delta \mathrm{S} / \mathrm{S}_{0}\right) d z}{1+\frac{2}{l} \int_{0}^{l} \cos ^{2}(\pi \dot{z} / l)\left(\delta \mathrm{S} / \mathrm{S}_{0}\right) d z}
\end{aligned}
$$

As $\delta \mathrm{S} / \mathrm{S}_{0}$ is by hypothesis everywhere small, we may neglect squares of either integral as compared to unity, and so deduce

$$
\begin{aligned}
k^{2} & =\frac{\mathrm{E}}{\rho}\left(\frac{\pi}{l}\right)^{2}\left\{1+\frac{2}{l} \int_{0}^{l}\left(\sin ^{2} \frac{\pi z}{l}-\cos ^{2} \frac{\pi z}{l}\right) \frac{\delta \mathrm{S}}{\mathrm{S}_{0}} d z\right\} \\
& =\frac{\mathrm{E}}{\rho}\left(\frac{\pi}{l}\right)^{2}\left\{1-\frac{2}{l} \int_{0}^{l} \frac{\delta \mathrm{S}}{\mathrm{S}_{0}} \cos \frac{2 \pi z}{l} d z\right\} . . . .
\end{aligned}
$$

Now suppose that the rod has the same period as if it possessed a uniform section but were of slightly different length $l+\delta l$. Then

$$
k^{2}=\frac{\mathrm{E}}{\rho} \frac{\pi^{2}}{(l+\delta l)^{2}}=\frac{\mathrm{E}}{\rho} \frac{\pi^{2}}{l^{2}}\left\{1-\frac{2 \delta l}{l}\right\} \ldots .
$$

Comparing the identities (4) and (5) we deduce at once 
Mr. Bell's formula

$$
\delta l=\int_{0}^{l} \frac{\delta \mathrm{S}}{\mathrm{S}_{0}} \cos \frac{2 \pi z}{l} d z . . . . .
$$

This gives the correction $\delta l$ necessary to obtain the length of the equivalent rod of uniform section.

The proof does not assume $\mathrm{S}_{0}$ to be the mean area of the cross section. But the assumptions that $\delta \mathrm{S} / \mathrm{S}_{0}$ is everywhere very small, and that the squares of the integrals in (3) are negligible, will be in general most satisfactorily fulfilled when $\mathrm{S}_{0}$ is the mean section.

When $\mathrm{S}$ is more than usually variable, a slight increase in accuracy would probably be obtained by determining $k$ directly from (3). In this event it would be convenient that $S$, should be the mean section, as we should then have

and so

$$
\int_{0}^{l}\left(\cos ^{2} \frac{\pi z}{l}+\sin ^{2} \frac{\pi z}{l}\right) \frac{\delta S}{\mathrm{~S}_{0}} d z=0
$$

$$
\int_{0}^{l} \cos ^{2} \frac{\pi z}{l} \cdot \frac{\delta \mathrm{S}}{\mathrm{S}_{0}} d z=-\int_{0}^{l} \sin ^{2} \frac{\pi z}{l} \cdot \frac{\delta \mathrm{S}}{\mathrm{S}_{0}} d z=\frac{1}{z} \int_{0}^{l} \cos \frac{2 \pi z}{l} \cdot \frac{\delta \mathrm{S}}{\mathrm{S}_{0}} d z .
$$

We should thus bave still really only one integral to evaluate.

If the tube were fixed-fixed instead of free-free, the origin being still at an end, we should obtain for the correction to the length

$$
\delta l=-\int_{0}^{l}\left(\delta \mathrm{S} / \mathrm{S}_{0}\right) \cos (2 \pi z / l) d z . . .
$$

This is numerically equal but opposite in sign to the correction obtained for the free-free rod; thus by combining results from the two species of vibrations we could eliminate the effects of variation of section, assuming them of course to be small.

In a fixed-free bar, $z=0$ being the fixed end, we find

$$
\delta l=-\int_{0}^{l}\left(\delta \mathrm{S} / \mathrm{S}_{0}\right) \cos (\pi z / l) d z . \quad . \quad .
$$

In all these cases an increase of $S$ near a fixed end or node tends to make $\delta l$ negative or raises the pitch, while an increase of $\mathbf{S}$ near a free end tends to make $\delta l$ positive. In other words; an increase of material stiffens the bar elastically when near a node, but acts mainly as a load when occurring near a section of maximum amplitude of motion. 